\title{
Self-reported rate of eating and prevalence of obesity among children in the great east Japan earthquake affected prefecture
}

\author{
A. Nishide ${ }^{1}$, H. Matsubara ${ }^{2}$, M. Nagai ${ }^{2}$, S. Kure ${ }^{2,3}$ and S. Kuriyama ${ }^{1}$ \\ ${ }^{1}$ International Research Institute of Disaster Science, Tohoku University, Sendai, Japan, ${ }^{2}$ Tohoku Medical Megabank \\ Organization, Tohoku University, Sendai, Japan and ${ }^{3}$ Department of Pediatrics, Graduate School of Medicine, Tohoku \\ University, Sendai, Japan.
}

An immediate weight gain among children in the great east Japan earthquake affected prefectures, that could presume due to the change of eating behaviour after the earthquake, was reported ${ }^{(1)}$. Eating behaviour, such as eating quickly, has been advised for weight management. Slower eating might allow satiation to register before having too much food ${ }^{(2)}$. Several previous observation studies $^{(3,4)}$ have shown the association between eating speed and prevalence of obesity in Japanese children using the data of children in where was not affected by the disaster. Thus, the aim of this study was to investigate whether the association between eating speed and prevalence of obesity might presence among children in the affected area.

We conducted a cross-sectional study using the baseline data of cluster randomization trial involving one affected primary school, which was defined by the location where has over $5 \%$ of fatality rate by the disaster ${ }^{(5)}$, and five non-affected school in the city of Miyagi prefecture. Brief self- administered diet history questionnaire was distributed to the parents of all six school children in first grade to fifth grade aged $6 \mathrm{yr}$ to $11 \mathrm{yr}$ on August 29th, $2017(\mathrm{n}=1397)$. Study participants were 403 children whose parents returned the questionnaires (response rate: $28.8 \%$ ). Of these, we analysed 402 children after excluding child who answered "unknown" for its eating speed. Eating speed was defined as item ("How fast is your rate of eating?") of which answers were chosen from five qualitative categories, which were divided into three categories as fast (very fast or fast), moderate (moderate), and slow (slow or very slow). Obesity was defined as obesity index; (real weight - standard weight)/standard weight $\times 100$, more than $20 \%{ }^{(6)}$. We used logistic regression analysis to estimate multivariate adjusted odds ratio (OR), $95 \%$ confidence interval (CI) for prevalence of obesity in each eating speed category, with the moderate in non-affected used as a reference.

Table 1. Odds ratios (ORs) and $95 \%$ confidence intervals (CIs) of obesity by three categories of eating speed.

\begin{tabular}{|c|c|c|c|c|c|c|}
\hline & \multirow[b]{3}{*}{ Eating Speed } & \multirow[b]{3}{*}{$\mathrm{n}$} & \multicolumn{4}{|c|}{ affected school } \\
\hline & & & \multirow[b]{2}{*}{ OR } & \multicolumn{2}{|c|}{$95 \% \mathrm{CI}$} & \multirow[b]{2}{*}{$\mathrm{p}$} \\
\hline & & & & low & upper & \\
\hline \multirow[t]{3}{*}{ affected } & fast & 28 & $4 \cdot 18$ & 1.43 & $12 \cdot 21$ & 0.009 \\
\hline & moderate & 51 & 1.65 & 0.55 & 4.98 & $0 \cdot 370$ \\
\hline & slow & 45 & 0.61 & $0 \cdot 15$ & $2 \cdot 37$ & 0.472 \\
\hline \multirow[t]{3}{*}{ non-affected } & fast & 67 & 3.78 & 1.56 & $9 \cdot 16$ & $0 \cdot 003$ \\
\hline & moderate & 107 & 1.00 & (ref) & & \\
\hline & slow & 104 & 0.69 & $0 \cdot 24$ & 1.94 & 0.480 \\
\hline
\end{tabular}

Compared with moderate speed of eating in non-affected, "fast" was significantly associated with a higher prevalence of obesity in both affected and non-affected school $(p=0.009, p=0.003)$. Odds ratio of fast in affected was slightly higher than this in non-affected, but not huge different. This study has limitations that we did not actually observe the eating speed and anthropometry, because these data were obtained from self-administered questionnaires. Although this limitation, the results could be interpreted the association between rate of eating and prevalence of obesity among children in affected school might not be effected by the disaster. To determine the factors to associate with an immediate weight gain among children after the disaster, further studies with an assessment at immediately after disaster was needed.

1. Matsubara H, Ishikuro M, Kikuya M et al. (2016) Journal epidemiol 26(2), 98-104.

2. Viskaal-van DM, Kok FJ \& de Graaf C (2011) Appetite 56(1), 25-31.

3. Murakami K, Miyake Y, Sasaki S et al. (2012) J Nutr Sci Vitaminol 58(4), 247-252.

4. Okubo H, Miyake Y, Sasaki S et al. (2017) Nutr Res 37, 20-28.

5. Tani K (2012) Saitama University Department Geography occasional paper 32, 1-26. (in Japanese).

6. Ikiuo K, Hashimoto R \& Murata M (2010) J child health 69, 6-13. (in Japanese). 